\title{
Article \\ Psychometric Properties of the Schizophrenia Oral Health Profile: Preliminary Results
}

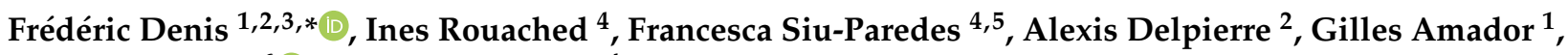 \\ Wissam El-Hage ${ }^{6}\left(\mathbb{D}\right.$ and Nathalie Rude ${ }^{4}$
}

1 Faculty of Dentistry, Nantes University, 44000 Nantes, France; gilles.amadordelvalle@chu-nantes.fr

2 Department of Odontology, Tours University Hospital, 37000 Tours, France; alexis.delpierre@outlook.fr

3 EA 75-05 Education, Ethique, Santé, Faculté de Médecine, Université de Tours, 37000 Tours, France

4 EA 481 Integrative and Clinical Neurosciences, University of Besançon, 25000 Besançon, France; ines.rouached@edu.univ-fcomte.fr (I.R.); chinitasiu@hotmail.com (F.S.-P.); nathalie.retel-rude@univ-fcomte.fr (N.R.)

5 Faculté d'Odontologie de Reims, Université Champagne Ardenne, 51100 Reims, France

6 U1253, iBrain, CIC1415, Inserm, CHRU de Tours (Regional University Hospital Centre), Université de Tours, 37000 Tours, France; wissam.elhage@univ-tours.fr

* Correspondence: frederic.denis@chu-tours.fr

check for

updates

Citation: Denis, F.; Rouached, I.; Siu-Paredes, F.; Delpierre, A.; Amador, G.; El-Hage, W.; Rude, N. Psychometric Properties of the Schizophrenia Oral Health Profile: Preliminary Results. Int. J. Environ. Res. Public Health 2021, 18, 9090. https://doi.org/10.3390/ ijerph18179090

Academic Editor: Yoko Hasegawa

Received: 29 July 2021

Accepted: 24 August 2021

Published: 28 August 2021

Publisher's Note: MDPI stays neutral with regard to jurisdictional claims in published maps and institutional affiliations.

Copyright: (c) 2021 by the authors. Licensee MDPI, Basel, Switzerland. This article is an open access article distributed under the terms and conditions of the Creative Commons Attribution (CC BY) license (https:// creativecommons.org/licenses/by/ $4.0 /)$.

\begin{abstract}
The Schizophrenia Oral Health Profile questionnaire was developed to assess the oral health-related quality of life among individuals with schizophrenia based on their perceptions rather than from caregivers. A 5-point Likert scale was used to self-report on 42 items. In the present study, different analyses were conducted to determine the dimensional structure of the final scale: (1) interitem correlation analysis and Cronbach's $\alpha$ coefficient, (2) Rasch model analysis, (3) exploratory factor analysis and (4) confirmatory factor analysis. The final version of the Schizophrenia Oral Health Profile questionnaire consisted of 20 items and an internal structure composed of three dimensions: (1) emotions related to oral health, (2) oral pain and discomfort and (3) self-image, others' views and the need for care. We showed that the difficulty and discrimination indices of each of the 20 selected items were acceptable according to the Rasch model, as well as their inter-item and inter-score correlations $(\alpha=0.875)$. The psychometric study of the Schizophrenia Oral Health Profile questionnaire is still in progress to investigate reproducibility, sensitivity to change and external structure.
\end{abstract}

Keywords: schizophrenia; psychometric; oral health-related quality of life; oral health

\section{Introduction}

When people suffer from a severe mental illness such as schizophrenia, it is difficult to know how they perceive their physical symptoms and, more broadly, how they feel in terms of their health needs and quality of life. Indeed, positive symptoms such as hallucinations and dysfunctional thought patterns, negative symptoms associated with emotional and behavioural disturbances and cognitive symptoms manifest as difficulties in comprehension, decision-making and attention, which combine to deleteriously impact the daily functioning of these people [1]. In this context, people with schizophrenia (PWS) may have difficulties in expressing their physical health needs and accessing health services. It is estimated that, in this population, half of the physical disorders (e.g., cardiovascular, gastrointestinal, respiratory, neoplastic, infectious, endocrine and oral) are undiagnosed [2,3].

The oral health of PWS is poor compared with that of the general population, and indices of dental caries and periodontal measurements are often twice the level found in the general population [4-6]. We now know that many factors combine to contribute to poor oral health in these individuals. These factors include poor diet and lifestyle 
behaviours (high-sugar diet, use of psychoactive substances such as tobacco and inadequate oral hygiene) as well as the side effects of antipsychotic treatments [7]. It is also worth mentioning that the weight of stigmatisation or self-stigmatisation limits patient access to the health care system $[3,8]$.

Knowing the perceived oral health needs as well as the representations and perceptions related to oral disorders or oral health-related quality of life (OHrQoL) in schizophreniarelated disorders is essential to effective care and to build adapted care strategies but also to develop prevention and promotion programmes for this health issue. To evaluate the relevance of these actions, reliable and valid measurement tools are needed. Even though we have established the reliability and validity of the Global Oral Health Assessment Index (GOHAI) scale in a French representative sample of PWS [9], the side effects of psychostimulants or antipsychotics, which include trismus, facial muscle pain, myasthenia or dyskinesia (tremors) or drooling with clozapine, are not captured by this scale.

A recent study presents the different stages of the development of the "Schizophrenia Oral Health Profile" (SOHP) questionnaire, which aims to assess oral disorders and their impact on the psychosocial functioning and well-being of PWS [10]. This work was conducted in close collaboration with health professionals and PWS. The approach in establishing the SOHP questionnaire was based on comments made by patients ( $74 \%$ of the items were generated by PWS) and health professionals during semi-structured interviews. The results of this study led to the construction of a provisional self-questionnaire composed of 42 items assessed using a 5-point Likert scale from which three assumed dimensions emerged: one dimension related to pain, one related to oral dysfunctions and the last related to the psychosocial impacts of oral disease.

The present study aimed to investigate the psychometric properties of the provisional SOHP questionnaire.

\section{Materials and Methods}

\subsection{Research Design}

As a first step, from June 2016 to November 2018, a qualitative study was conducted to explore the importance values of OHrQOL for PWS. From this study, a conceptual questionnaire of 42 items was obtained. This first step was conducted at the Chartreuse Hospital (Dijon, France) with 34 people (24 PWS and 10 health professionals) [10]. In a second step, the psychometric properties (internal consistency and reliability) of this questionnaire were explored with a large sample of SPWs recruited in five French hospitals from September 2018 to June 2021. The psychometric study of the SOHP scale is ongoing to investigate the reproducibility, sensitivity to change and external structure of this scale. The study was registered with www.ClinicalTrials.gov, accessed on 9 October 2018 under the number NCT03699501.

Below, Figure 1 summarises the research design used in the present study.

\subsection{Analysis}

To investigate the psychometric properties of the provisional SOHP questionnaire, we used (1) inter-item correlation analysis and Cronbach's $\alpha$ coefficient, (2) Rasch model analysis, (3) exploratory factor analysis (EFA) and (4) confirmatory factor analysis (CFA).

\subsubsection{Inter-Item Correlation and Cronbach's $\alpha$ Coefficient}

Internal consistency was assessed using Cronbach's $\alpha$ coefficient and inter-item correlation [11,12]. Cronbach's $\alpha$ values greater than 0.75 indicate excellent reliability, values between 0.40 and 0.75 show fair to good reliability, and values less than 0.40 indicate poor reliability $[11,12]$. 


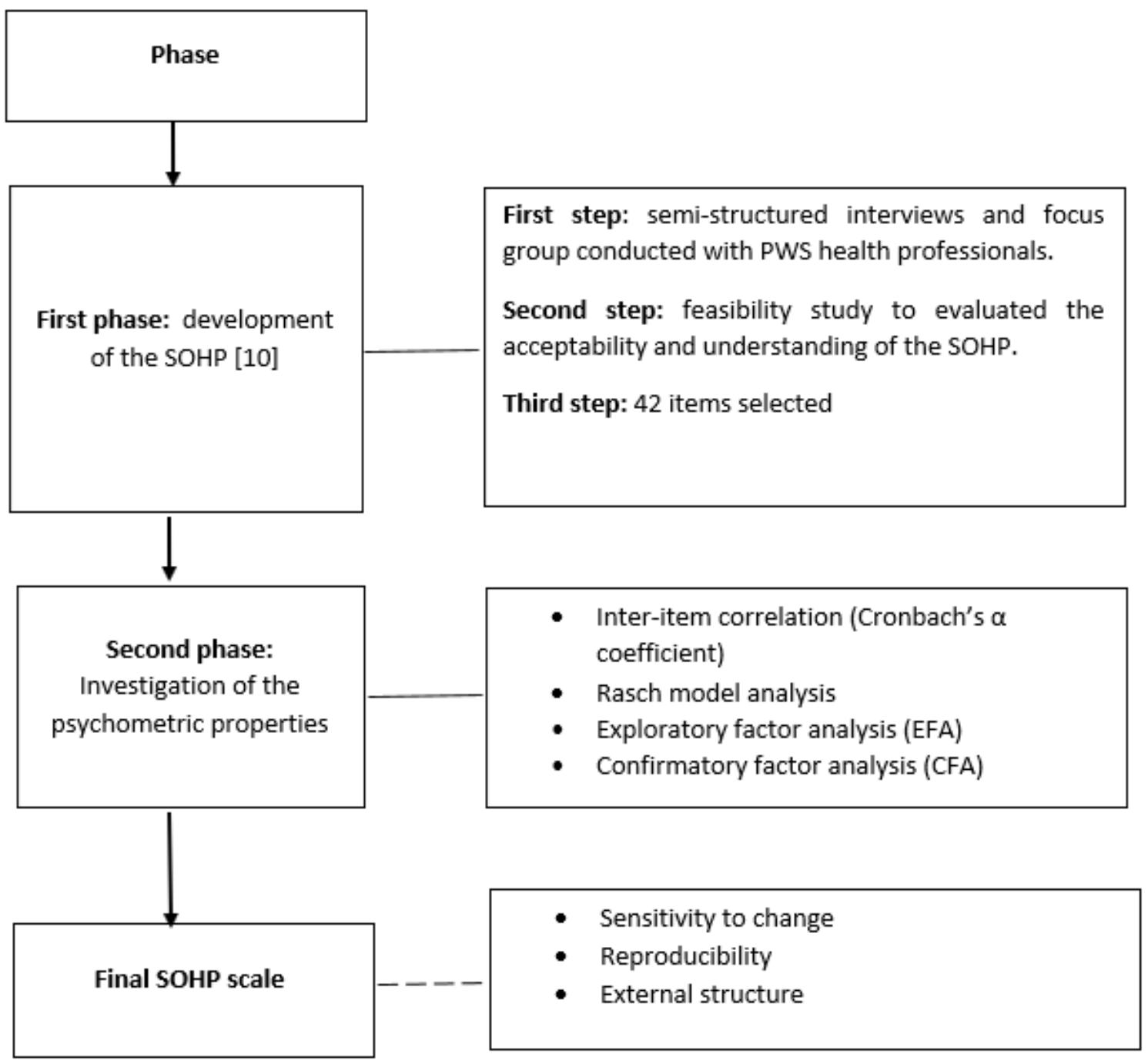

Figure 1. Process of program development and psychometric testing. SOHP: Schizophrenia Oral Health Profile; PWS: people with schizophrenia.

\subsubsection{Rasch Model Analysis}

The Rasch model was used to examine how well the provisional SOHP questionnaire functioned as a measurement of oral disorders and their impact on the psychosocial functioning and well-being of PWS by analysing how closely the observed item ratings matched those expected by the model. The Rasch model considered the different aspects of the measurement system, including items and rating scale categories, influencing the score [13]. As the aim was to refine the provisional instrument, the analysis was primarily used to highlight items or rating categories that showed substantial 'misfit' to the model, suggesting they may not usefully contribute, or may even degrade, the instrument's performance as a measurement system, and may need deleting.

\subsubsection{Exploratory Factor Analysis (EFA)}

EFA is a common technique used to explore the characteristics of an instrument and guide its development without any assumptions about the number or structure of this instrument [14,15]. EFA is often used in addition to Rasch analysis [16]. This analysis also aims to determine whether the correlations between items justify the belief that the items measure the same trait. If the items are not unidimensional, the scale may need to be divided into subscales, or items may need to be deleted (Kaiser-Meyer-Olkin-MO, value $>0.6$ and Bartlett test results showing significant sphericity) [14-16]. 


\subsubsection{Confirmatory Factor Analysis (CFA)}

CFA was conducted to check the data collected and the stability of the factor structure of the final version of the SOHP scale. The goodness of fit was assessed using chi-square/df, root mean square error of approximation (RMSEA), comparative fit index (CFI) and IFI (incremental fit index) [17].

\subsection{Sample}

The evaluation of the SOHP scale was conducted with PWS in several psychiatric institutions (Dijon, Tours, Millau, Reims, Paris). The expected number of subjects using G* Power R (wp.logistic) [15], a sample size program based on Cohen's sampling formula, was set at a significance level of 0.05 , a power of 0.80 and an effect size of 0.30 per 100 persons. The PWS were selected between September 2018 and June 2021.

\subsection{Ethical Considerations}

This study, named "Quality bis", was approved by the Committee for the Protection of Persons of the Ile de France region (registration number: 2018-A02043-52). After providing participants with a complete description of the study, informed consent was obtained from each participant or their legal guardians for individuals under guardianship. In the latter case, the patient's legal guardian(s) signed the informed consent.

\subsection{Data Analysis}

The analysis was conducted using software package R (Bell Laboratories, New Providence, NJ, USA).

\section{Results}

\subsection{Participants' General Characteristics}

For the 102 PWS who participated in the "Quality bis" study, there was very little missing data from the 42 -item SOHP questionnaire (less than 5\%), see Table 1.

Table 1. Participants' characteristics $(n=102)$.

\begin{tabular}{|c|c|}
\hline Variables & Mean \pm SD or $n(\%)$ \\
\hline Gender (male) & $69(67.6 \%)$ \\
\hline La Chartreuse Hospital Center (male) & $8(61.5 \%)$ \\
\hline Reims University Hospital Center (male) & $7(87.5 \%)$ \\
\hline Tours University Hospital Center (male) & $12(55 \%)$ \\
\hline Millau Hospital Center (male) & $26(78.7)$ \\
\hline $\begin{array}{c}\text { University Hospital Group Paris Psychiatry \& } \\
\text { Neurosciences (male) }\end{array}$ & $16(70 \%)$ \\
\hline Age (years) & $40.7 \pm 11.5$ \\
\hline \multicolumn{2}{|l|}{ Marital status } \\
\hline Married/cohabitation & $4(3.9 \%)$ \\
\hline Single & $76(74.5 \%)$ \\
\hline Duration of psychiatric care (month) & $156.3 \pm 121.4$ \\
\hline Number of antipsychotic treatments & $2.0 \pm 1.3$ \\
\hline Other drug therapy & $3.7 \pm 3.0$ \\
\hline Smoker & $46(45.1 \%)$ \\
\hline Number of cigarettes a day & $14.6 \pm 8.0$ \\
\hline Number of carious teeth & $3.1 \pm 3.3$ \\
\hline Number of missing teeth & $5.3 \pm 5.0$ \\
\hline Number of filled teeth & $4.0 \pm 5.5$ \\
\hline DMFT index * & $13.3 \pm 7.4$ \\
\hline OHI-S index ** & $1.6 \pm 1.0$ \\
\hline
\end{tabular}

* DMFT, Decayed, Missing, or Filled Teeth (DMFT) index [18]; ** OHI-S, Simplified Oral Hygiene Index (OHI-S) [19]. 


\subsection{The Psychometric Properties of the Provisional SOHP Questionnaire (42 Items)}

3.2.1. Inter-Item Correlation

The correlation of each item ( 1 to 42 ) of the SOHP is presented in Table 2.

Table 2. Inter-item correlation for the SOHP (42 items).

\begin{tabular}{rcccccccccc}
\hline SOPH Item & 1 & 2 & 3 & 4 & 5 & 6 & 7 & 8 & 9 \\
& 0.221 & 0.253 & -0.022 & 0.306 & 0.088 & 0.204 & 0.128 & 0.436 & 0.248 \\
SOPH Item & 10 & 11 & 12 & 13 & 14 & 15 & 16 & 17 & 18 \\
& 0.395 & 0.437 & 0.279 & 0.234 & 0.485 & 0.424 & 0.400 & 0.383 & 0.200 \\
SOPH Item & 19 & 20 & 21 & 22 & 23 & 24 & 25 & 26 & 27 \\
& 0.245 & 0.376 & 0.253 & 0.283 & 0.211 & 0.429 & 0.499 & 0.484 & 0.374 \\
SOPH Item & 28 & 29 & 30 & 31 & 32 & 33 & 34 & 35 & 36 \\
& 0.239 & 0.389 & 0.279 & 0.122 & 0.199 & 0.440 & 0.391 & 0.212 & 0.238 \\
SOPH Item & 37 & 38 & 39 & 40 & 41 & 42 & & \\
& 0.228 & 0.328 & 0.348 & 0.391 & 0.284 & -0.067 & & \\
\hline
\end{tabular}

SOHP: Schizophrenia Oral Health Profile.

Inter-item correlations are an essential element in conducting an item analysis of a set of test questions. Inter-item correlations examine the extent to which scores on one item are related to scores on all other items on a scale. Ideally, the average inter-item correlation for a set of items should be between 0.20 and 0.40 , suggesting that while the items are reasonably homogenous, they do contain sufficiently unique variance so as to not be isomorphic with each other. When values are lower than 0.20 , then the items may not be representative of the same content domain. If values are higher than 0.40 , the items may be only capturing a small bandwidth of the construct.

\subsubsection{Rasch Model Analysis}

The average of the values of the response modalities was between 1 and 4 , with standard deviations varying between 0.5 and 1.5 for each item (Table 3 ).

Initially, the items with a discrimination index that was negative or close to 0 were removed ( $\mathrm{S} 3$ and $\mathrm{S} 42$ ). Then, the misfit items that did not meet the standard criteria of fit statistics were excluded [13]. Thus, items S2, S3, S4, S5, S6, S7, S9, S13, S23, S28, S29, S30, S31, S32, S33, S34, S35, S36, S38, S39, S40 and S42 were excluded from the scale. The SOHP was then reduced from 42 to 20 items.

\subsubsection{Exploratory Factor Analysis (EFA)}

EFA was performed on the 42 items to search for possible dimensions and to confirm the exclusion of the 22 items previously removed after the Rasch analysis. Figure 2 allows us to determine by which factor (or factorial dimension) the items are best represented.

Figure 3 shows that the first axis of the PCA concentrates 19.3\% of the information. The second, third, fourth, fifth and sixth axes each contain 10.10\%, 5.9\%, 5.1\%, 4.6\% and $4.1 \%$, respectively. We have about $49.1 \%$ of the total variance explained by the first six axes. 
Table 3. Rasch analysis of the SOHP (42 items).

\begin{tabular}{|c|c|c|c|c|c|c|c|c|c|}
\hline Item & Missing & Mean & SD & Skew & Kurtosis & $\mathbf{W}(p)$ & $\begin{array}{c}\text { Item } \\
\text { Difficulty }\end{array}$ & $\begin{array}{c}\text { Item } \\
\text { Discrimination }\end{array}$ & $\begin{array}{c}\alpha \text { If } \\
\text { Deleted }\end{array}$ \\
\hline 1: I have anxiety attacks & $1.96 \%$ & 2.2 & 1.31 & 0.64 & -0.87 & $0.81(0.000)$ & 0.44 & 0.23 & 0.81 \\
\hline 2: I take things easy, without feeling stressed & $2.94 \%$ & 3.39 & 1.35 & -0.5 & -0.82 & $0.87(0.000)$ & 0.68 & 0.25 & 0.81 \\
\hline $\begin{array}{l}\text { 3: My living conditions are pleasant (food, } \\
\text { accommodation, transport) }\end{array}$ & $3.92 \%$ & 3.49 & 1.26 & -0.68 & -0.55 & $0.86(0.000)$ & 0.70 & -0.12 & 0.82 \\
\hline 4: I engage in physical activity & $3.92 \%$ & 3.55 & 1.15 & -071 & -0.10 & $0.87(0.000)$ & 0.71 & 0.41 & 0.81 \\
\hline 5: I feel physically well & $3.92 \%$ & 3.36 & 1.21 & -0.3 & -0.80 & $0.90(0.000)$ & 0.67 & 0.09 & 0.82 \\
\hline 6: I sleep well & $2.94 \%$ & 3.86 & 1.12 & -0.84 & -0.00 & $0.85(0.000)$ & 0.77 & 0.30 & 0.81 \\
\hline 8: My teeth hurt & $1.96 \%$ & 1.99 & 1.13 & 1.04 & -0.43 & $0.80(0.000)$ & 0.40 & 0.36 & 0.81 \\
\hline 9: My jaw hurts & $7.84 \%$ & 2.93 & 1.49 & 0.05 & -1.45 & $0.87(0.000)$ & 0.59 & 0.29 & 0.81 \\
\hline 10: I have muscular pain in my face & $1.96 \%$ & 1.45 & 0.9 & 2.17 & 4.39 & $0.57(0.000)$ & 0.29 & 0.40 & 0.81 \\
\hline 11: My jaw and my teeth don't feel right & $2.94 \%$ & 1.67 & 1.25 & 1.71 & 1.54 & $0.58(0.000)$ & 0.33 & 0.44 & 0.81 \\
\hline 12: I'm lost in thought; I'm rehashing my memories & $2.94 \%$ & 3 & 1.21 & -021 & -0.80 & $0.90(0.000)$ & 0.60 & 0.28 & 0.81 \\
\hline 13: I am self-confident, I have good self-esteem & $1.96 \%$ & 3.09 & 1.16 & -0.06 & -0.85 & $0.92(0.000)$ & 0.62 & 0.25 & 0.81 \\
\hline 14: Because of how my mouth looks, I'm afraid of how others see me & $2.94 \%$ & 2.12 & 1.33 & 0.75 & -0.82 & $0.78(0.000)$ & 0.42 & 0.38 & 0.81 \\
\hline 15: I need care for my oral well-being (for my oral and dental health) & $1.96 \%$ & 3.28 & 1.36 & -0.3 & -1.10 & $0.89(0.000)$ & 0.66 & 0.44 & 0.81 \\
\hline 16: My mouth is sensitive to hot and cold & $2.94 \%$ & 2.37 & 1.37 & 0.54 & -0.93 & $0.84(0.000)$ & 0.47 & 0.31 & 0.81 \\
\hline 18: I find it hard to swallow comfortably & $2.94 \%$ & 1.65 & 0.93 & 1.31 & 1.02 & $0.71(0.000)$ & 0.33 & 0.20 & 0.81 \\
\hline 19: I have bad breath & $1.96 \%$ & 2.06 & 1.18 & 0.86 & -0.13 & $0.81(0.000)$ & 0.41 & 0.25 & 0.81 \\
\hline 20: I grind my teeth & $1.96 \%$ & 1.59 & 0.96 & 1.53 & 1.41 & $0.66(0.000)$ & 0.32 & 0.37 & 0.81 \\
\hline 21: My gums bleed & $1.96 \%$ & 1.98 & 1.15 & 0.86 & -0.28 & $0.80(0.000)$ & 0.52 & 0.26 & 0.81 \\
\hline 22: My mouth feels dry or sticky & $1.96 \%$ & 2.6 & 1.24 & -1.21 & -1.21 & $0.87(0.000)$ & 0.76 & 0.26 & 0.81 \\
\hline 23: I can articulate sounds correctly & $2.94 \%$ & 3.79 & 1.29 & -0.65 & -078 & $0.83(0.000)$ & 0.76 & 0.26 & 0.81 \\
\hline 24: I have difficulty chewing & $2.94 \%$ & 1.93 & 1.19 & 1.03 & -0.02 & $0.77(0.000)$ & 0.39 & 0.48 & 0.81 \\
\hline 25: I'm worried about my oral health & $3.92 \%$ & 3.05 & 1.41 & -0.11 & -1.32 & $0.88(0.000)$ & 0.61 & 0.48 & 0.81 \\
\hline 26: I am embarrassed to speak because of the state of my mouth & $2.94 \%$ & 1.82 & 1.23 & 1.36 & 0.69 & $0.70(0.000)$ & 0.36 & 0.38 & 0.81 \\
\hline 27: I'm embarrassed to smile because of the state of my mouth & $3.92 \%$ & 2.33 & 1.54 & 0.61 & -1.20 & $0.77(0.000)$ & 0.47 & 0.35 & 0.81 \\
\hline 28: I pay attention to my breath & $1.96 \%$ & 3.08 & 1.45 & -0.16 & -1.30 & $0.88(0.000)$ & 0.62 & 0.15 & 0.82 \\
\hline 29: I am motivated to brush my teeth & $2.94 \%$ & 3.45 & 1.43 & -0.57 & -1.03 & $0.84(0.000)$ & 0.69 & 0.41 & 0.81 \\
\hline 30: I hate brushing my teeth & $2.94 \%$ & 1.51 & 1 & 2.06 & 3.52 & $0.57(0.000)$ & 0.30 & 0.15 & 0.81 \\
\hline
\end{tabular}


Table 3. Cont.

\begin{tabular}{|c|c|c|c|c|c|c|c|c|c|}
\hline Item & Missing & Mean & SD & Skew & Kurtosis & $\mathbf{W}(p)$ & $\begin{array}{c}\text { Item } \\
\text { Difficulty }\end{array}$ & $\begin{array}{c}\text { Item } \\
\text { Discrimination }\end{array}$ & $\begin{array}{c}\alpha \text { If } \\
\text { Deleted }\end{array}$ \\
\hline 31: I am open to meeting other people & $3.92 \%$ & 3.57 & 1.24 & -0.64 & -0.46 & $0.87(0.000)$ & 0.71 & 0.16 & 0.82 \\
\hline 32: I take care of myself (I do my hair, wear make-up, shave ... ) & $2.94 \%$ & 3.78 & 1.19 & -0.74 & -0.40 & $0.85(0.000)$ & 0.76 & 0.21 & 0.81 \\
\hline 34: I talk to my family about my oral health problems & $22.55 \%$ & 1.91 & 1.31 & 1.21 & 0.18 & $0.71(0.000)$ & 0.38 & 0.29 & 0.81 \\
\hline 35: I feel that my friend(s) are supportive towards me & $2.94 \%$ & 3.01 & 1.37 & -0.11 & -1.14 & $0.89(0.000)$ & 0.60 & 0.23 & 0.81 \\
\hline 36: I feel that my family is supportive towards me & $4.90 \%$ & 3.36 & 1.49 & -0.51 & -1.17 & $0.84(0.000)$ & 0.67 & 0.19 & 0.81 \\
\hline 37: I need help to manage my feelings & $3.92 \%$ & 2.5 & 1.29 & 0.27 & -1.04 & $0.87(0.000)$ & 0.50 & 0.28 & 0.81 \\
\hline 39: I have projects (for holidays, for work, for my family life) & $2.94 \%$ & 3.08 & 1.33 & -0.23 & -1.00 & $0.89(0.000)$ & 0.62 & 0.38 & 0.81 \\
\hline 40: I manage to organise all my activities and appointments & $3.92 \%$ & 3.48 & 1.33 & -0.67 & -0.63 & $0.86(0.000)$ & 0.70 & 0.36 & 0.81 \\
\hline 41: I need help to manage my health & $2.94 \%$ & 3.18 & 1.39 & -0.31 & -1.10 & $0.88(0.000)$ & 0.64 & 0.23 & 0.81 \\
\hline 42: I'm satisfied with my oral health & $4.90 \%$ & 3.14 & 1.34 & -0.24 & -1.09 & $0.89(0.000)$ & 0.63 & 0.00 & 0.82 \\
\hline
\end{tabular}

SD, standard deviation; mean inter-item correlation $=0.097$; Cronbach's $\alpha=0.816$. 


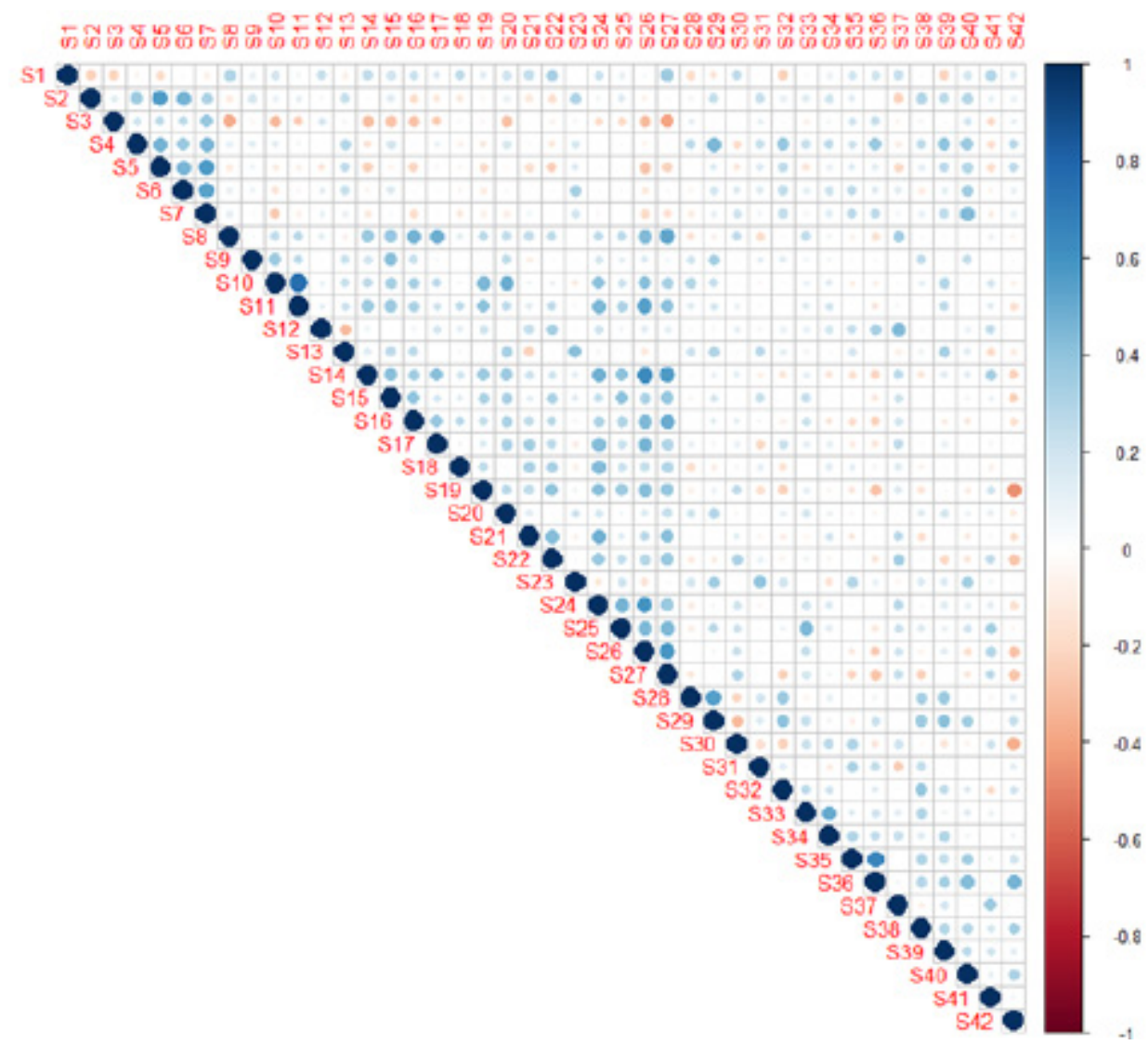

Figure 2. The SOHP item contribution matrix.

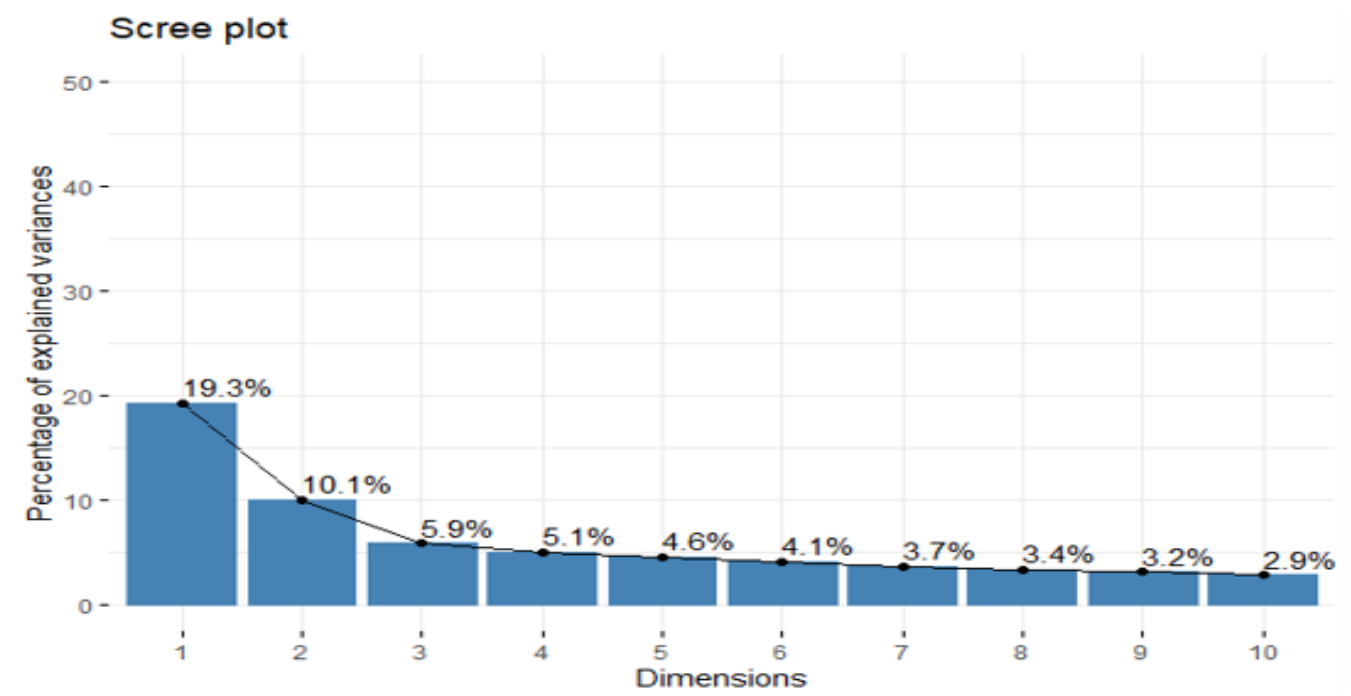

Figure 3. SOHP (42 items) eigenvalues graph.

3.2.4. Confirmatory Factor Analysis (CFA)

We found that the Rasch model eliminated 20 items outside the initial concept of quality of life. CFA was conducted to elicit more precise results on the validity of the 20-item SOHP. In the hierarchical analysis, we found that three groups were formed (Figure 4).

Figure 4 shows that items S8, 10, 11, 14, 17, 19, 20, 24, 26 and 27 were grouped in cluster 1. Items S12, 37 and 41 were grouped in cluster 2 and items S1, 15, 16, 18, 21, 22 and 25 were grouped in cluster 3 . 


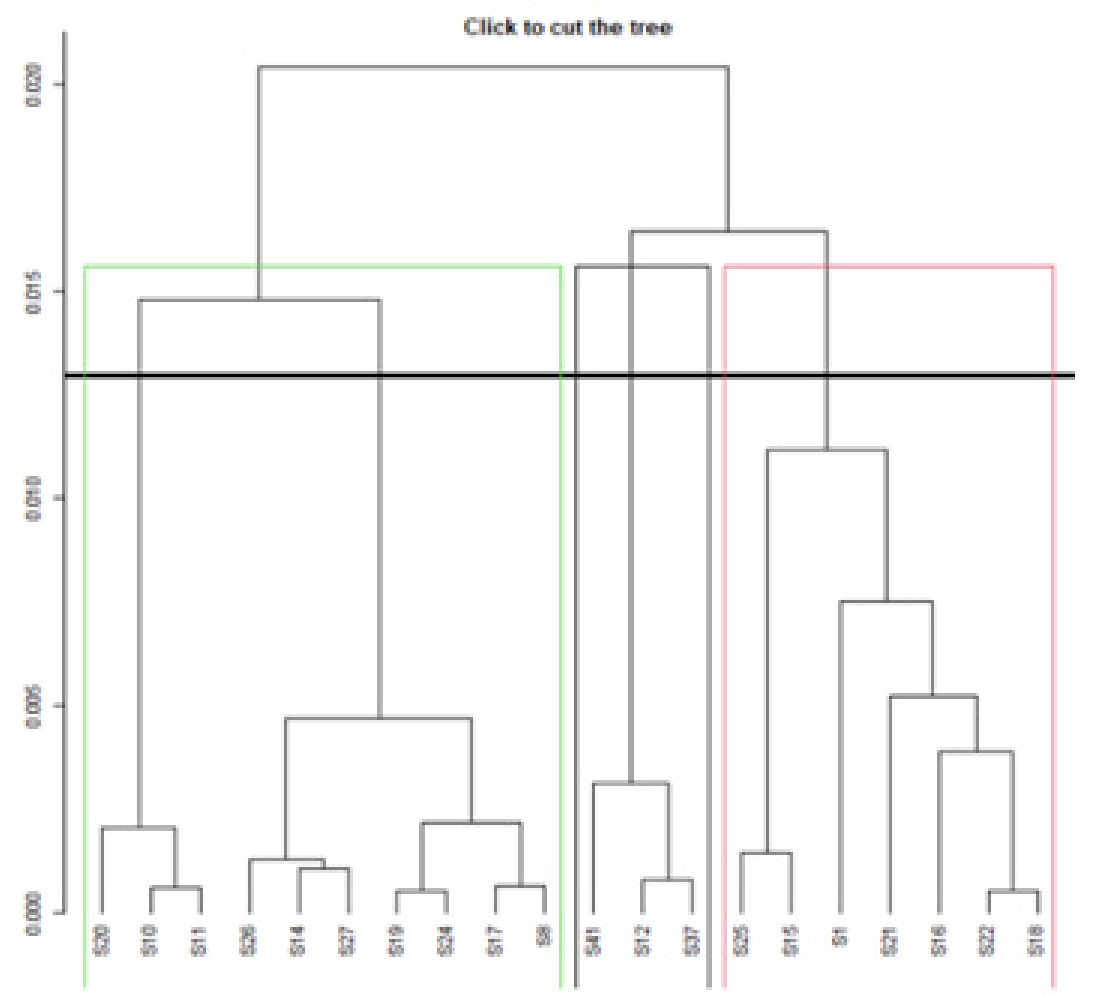

Figure 4. Individual items dendrogram for the SOHP scale with 20 items.

3.3. The Psychometric Properties of the Final SOHP Questionnaire (20 Items) 3.3.1. Inter-Item Correlation

The correlation of each item ( 1 to 20$)$ the SOHP score is presented in Table 4.

Table 4. Inter-item correlation for the SOHP 20 items.

\begin{tabular}{ccccccccccc}
\hline \multirow{2}{*}{ SOPH Item } & 1 & 8 & 10 & 11 & 12 & 14 & 15 & 16 & 17 & 18 \\
& 0.43 & 0.64 & 0.60 & 0.58 & 0.26 & 0.70 & 0.55 & 0.59 & 0.58 & 0.30 \\
SOPH Item & 19 & 20 & 21 & 22 & 24 & 25 & 26 & 27 & 37 & 41 \\
& 0.56 & 0.33 & 0.40 & 0.57 & 0.66 & 0.43 & 0.75 & 0.70 & 0.42 & 0.40 \\
\hline
\end{tabular}

\subsubsection{Rasch Model Analysis}

The results of the Rasch model analysis are presented in Table 5.

Table 5. Rasch analysis of the 20-item SOHP.

\begin{tabular}{cccccccccc}
\hline Item & Missing & Mean & SD & Skew & Kurtosis & W $(p)$ & $\begin{array}{c}\text { Item } \\
\text { Difficulty }\end{array}$ & $\begin{array}{c}\text { Item } \\
\text { Discrimination }\end{array}$ & $\begin{array}{c}\alpha \text { If } \\
\text { Deleted }\end{array}$ \\
\hline 1 & $1.96 \%$ & 2.2 & 1.31 & 0.64 & -0.87 & $0.81(0.000)$ & 0.44 & 0.40 & 0.87 \\
8 & $1.96 \%$ & 1.99 & 1.13 & 1.04 & 0.43 & $0.80(0.000)$ & 0.40 & 0.58 & 0.87 \\
10 & $1.96 \%$ & 1.45 & 0.9 & 2.17 & 4.39 & $0.57(0.000)$ & 0.29 & 0.51 & 0.87 \\
11 & $2.94 \%$ & 1.67 & 1.25 & 1.71 & 1.54 & $0.58(0.000)$ & 0.33 & 0.48 & 0.87 \\
12 & $2.94 \%$ & 3 & 1.21 & -0.21 & -0.80 & $0.90(0.000)$ & 0.60 & 0.28 \\
14 & $2.94 \%$ & 2.12 & 1.33 & 0.75 & -0.82 & $0.78(0.000)$ & 0.42 & 0.63 \\
15 & $1.96 \%$ & 3.28 & 1.36 & -0.3 & -1.10 & $0.89(0.000)$ & 0.66 & 0.54 & 0.86 \\
16 & $2.94 \%$ & 2.37 & 1.37 & -0.54 & -0.93 & $0.84(0.000)$ & 0.47 & 0.57 & 0.87 \\
17 & $1.96 \%$ & 1.7 & 0.95 & 1.36 & 1.59 & $0.74(0.000)$ & 0.34 & 0.50 & 0.86 \\
18 & $2.94 \%$ & 1.65 & 0.93 & 1.31 & 1.02 & $0.71(0.000)$ & 0.33 & 0.27 & 0.87 \\
19 & $1.96 \%$ & 2.06 & 1.18 & 0.86 & -0.13 & $0.81(0.000)$ & 0.41 & 0.50 & 0.87 \\
\hline
\end{tabular}


Table 5. Cont.

\begin{tabular}{cccccccccc}
\hline Item & Missing & Mean & SD & Skew & Kurtosis & W $(\boldsymbol{p})$ & $\begin{array}{c}\text { Item } \\
\text { Difficulty }\end{array}$ & $\begin{array}{c}\text { Item } \\
\text { Discrimination }\end{array}$ & $\begin{array}{c}\alpha \text { If } \\
\text { Deleted }\end{array}$ \\
\hline 20 & $1.96 \%$ & 1.59 & 0.96 & 1.53 & 1.41 & $0.66(0.000)$ & 0.32 & 0.23 & 0.88 \\
21 & $1.96 \%$ & 1.98 & 1.15 & 0.86 & -0.28 & $0.80(0.000)$ & 0.40 & 0.37 & 0.87 \\
22 & $1.96 \%$ & 2.6 & 1.24 & -0.01 & -1.21 & $0.87(0.000)$ & 0.52 & 0.54 & 0.87 \\
24 & $2.94 \%$ & 1.93 & 1.19 & 1.03 & -0.02 & $0.77(0.000)$ & 0.39 & 0.60 & 0.86 \\
25 & $3.92 \%$ & 3.05 & 1.41 & -0.11 & -1.32 & $0.88(0.000)$ & 0.61 & 0.41 & 0.87 \\
26 & $2.94 \%$ & 1.82 & 1.23 & 1.36 & 0.69 & $0.70(0.000)$ & 0.36 & 0.67 \\
27 & $3.92 \%$ & 2.33 & 1.54 & 0.61 & -1.20 & $0.77(0.000)$ & 0.47 & 0.68 & 0.86 \\
37 & $3.92 \%$ & 2.5 & 1.29 & 0.27 & -1.04 & $0.87(0.000)$ & 0.50 & 0.40 & 0.87 \\
41 & $2.94 \%$ & 3.18 & 1.39 & -0.31 & -1.10 & $0.88(0.000)$ & 0.64 & 0.33 & 0.88 \\
\hline
\end{tabular}

$\mathrm{SD}$, standard deviation; mean inter-item correlation $=0.258$; Cronbach's $\alpha=0.875$.

\subsubsection{The Three Dimensions of the Final Version of the SOHP (20 Items)}

As the factor analysis did not generate sub-themes (dimensions), we hypothesised that the items were grouped according to the proximity of their conceptual content. Therefore, we chose to construct dimensions based on conceptual similarity. Three dimensions emerged more precisely than in the first version of the questionnaire: (1) emotions related to oral health, (2) oral pain and discomfort and (3) self-image, others' views and the need for care.

Dimension 1 included seven items, S1, S12, S19, S20, S25, S26 and S37, all associated with the concept of emotions related to oral health (Table 6).

Table 6. The concept of emotions related to oral health.

\begin{tabular}{cccccccccc}
\hline Item & Missing & Mean & SD & Skew & Kurtosis & W $(p)$ & $\begin{array}{c}\text { Item } \\
\text { Difficulty }\end{array}$ & $\begin{array}{c}\text { Item } \\
\text { Discrimination }\end{array}$ & $\begin{array}{c}\alpha \text { If } \\
\text { Deleted }\end{array}$ \\
\hline 1 & $1.96 \%$ & 2.2 & 1.31 & 0.64 & -0.87 & $0.81(0.000)$ & 0.44 & 0.23 & 0.57 \\
12 & $2.94 \%$ & 3 & 1.21 & -0.21 & -0.80 & $0.90(0.000)$ & 0.60 & 0.30 & 0.54 \\
19 & $1.96 \%$ & 2.06 & 1.18 & 0.86 & -0.13 & $0.81(0.000)$ & 0.41 & 0.38 & 0.51 \\
20 & $1.96 \%$ & 1.59 & 0.96 & 1.53 & 1.41 & $0.66(0.000)$ & 0.32 & 0.16 & 0.58 \\
25 & $3.92 \%$ & 3.05 & 1.41 & -0.11 & -1.32 & $0.88(0.000)$ & 0.61 & 0.30 & 0.54 \\
26 & $2.94 \%$ & 1.82 & 1.23 & 1.36 & 0.69 & $0.70(0.000)$ & 0.36 & 0.40 & 0.50 \\
37 & $3.92 \%$ & 2.5 & 1.29 & 0.27 & -1.04 & $0.87(0.000)$ & 0.50 & 0.31 & 0.54 \\
\hline
\end{tabular}

$\mathrm{SD}$, standard deviation; mean inter-item correlation $=0.163$; Cronbach's $\alpha=0.579$.

Dimension 2 included eight items, S8, S10, S16, S17, S18, S21, S22 and S24, all associated with the concept of oral pain and discomfort (Table 7).

Table 7. The concept of oral pain and discomfort.

\begin{tabular}{cccccccccc}
\hline Item & Missing & Mean & SD & Skew & Kurtosis & W $(p)$ & $\begin{array}{c}\text { Item } \\
\text { Difficulty }\end{array}$ & $\begin{array}{c}\text { Item } \\
\text { Discrimination }\end{array}$ & $\begin{array}{c}\alpha \text { If } \\
\text { Deleted }\end{array}$ \\
\hline 8 & $1.96 \%$ & 1.99 & 1.13 & 1.04 & 0.43 & $0.80(0.000)$ & 0.40 & 0.56 & 0.73 \\
10 & $1.96 \%$ & 1.45 & 0.9 & 2.17 & 4.39 & $0.57(0.000)$ & 0.29 & 0.43 & 0.76 \\
16 & $2.94 \%$ & 2.37 & 1.37 & 0.54 & -0.93 & $0.84(0.000)$ & 0.47 & 0.55 & 0.73 \\
17 & $1.96 \%$ & 1.7 & 0.95 & 1.36 & 1.59 & $0.74(0.000)$ & 0.34 & 0.58 & 0.73 \\
18 & $2.94 \%$ & 1.65 & 0.93 & 1.31 & 1.02 & $0.71(0.000)$ & 0.33 & 0.29 & 0.78 \\
21 & $1.96 \%$ & 1.98 & 1.15 & 0.86 & -0.28 & $0.80(0.000)$ & 0.40 & 0.40 & 0.76 \\
22 & $1.96 \%$ & 2.6 & 1.24 & -0.01 & -1.21 & $0.87(0.000)$ & 0.52 & 0.43 & 0.76 \\
24 & $2.94 \%$ & 1.93 & 1.19 & 1.03 & -0.02 & $0.77(0.000)$ & 0.39 & 0.57 & 0.73 \\
\hline
\end{tabular}

$\mathrm{SD}$, standard deviation; mean inter-item correlation $=0.298$; Cronbach's $\alpha=0.772$.

Dimension 3 included five items, S11, S14, S15, S27 and S41, all associated with the concept of self-image, the gaze of others and the need for care (Table 8). 
Table 8. The concept of self-image, the gaze of others and the need for care.

\begin{tabular}{cccccccccc}
\hline Item & Missing & Mean & SD & Skew & Kurtosis & W $(p)$ & $\begin{array}{c}\text { Item } \\
\text { Difficulty }\end{array}$ & $\begin{array}{c}\text { Item } \\
\text { Discrimination }\end{array}$ & $\begin{array}{c}\alpha \text { If } \\
\text { Deleted }\end{array}$ \\
\hline 11 & $2.94 \%$ & 1.67 & 1.25 & 1.71 & 1.54 & $0.58(0.000)$ & 0.33 & 0.40 & 0.69 \\
14 & $2.94 \%$ & 2.12 & 1.33 & 0.75 & -0.82 & $0.78(0.000)$ & 0.42 & 0.66 \\
15 & $1.96 \%$ & 3.28 & 1.36 & -0.3 & -1.10 & $0.89(0.000)$ & 0.66 & 0.42 \\
27 & $3.92 \%$ & 2.33 & 1.54 & 0.61 & -1.20 & $0.77(0.000)$ & 0.47 & 0.62 \\
41 & $2.94 \%$ & 3.18 & 1.39 & -031 & -1.10 & $0.88(0.000)$ & 0.64 & 0.68 \\
\hline
\end{tabular}

$\mathrm{SD}$, standard deviation; mean inter-item correlation $=0.328$; Cronbach's $\alpha=0.711$.

\section{Discussion}

The SOHP was developed for measuring the OHrQoL of PWS. We showed that the difficulty and discrimination indices of each of the 20 items selected for the final version are acceptable according to the Rasch model, as are the inter-item (0.258) and inter-score correlations $(\alpha=0.875)$. We highlighted three dimensions in the final version of the psychometrically validated SOHP, (1) emotions related to oral health, (2) oral pain and discomfort and (3) self-image, others' view and the need for care.

Regarding dimension 1, the effects of oral health conditions on physical and psychosocial dimensions have been a topic of interest for several authors over the last decades [20,21]. Like Settineri et al. [22], we found a significant relationship between the patient's perception of oral health and their mood states: "Item 25: I am worried about my oral health", "Item 26. I am embarrassed to speak because of the condition of my mouth", "Item 19: I have bad breath". Item 20: "I grind my teeth, highlights a physical expression of stress and/or anxiety in the form of teeth grinding" [23]. These items allow a better understanding of the psychological mechanisms involved in treatment adherence and should allow the carers to focus on the elements of the oral disorder that are most meaningful to the patient rather than what they think is best.

Teeth have a symbolic value in emotional life insofar as the mouth, the main organ of our expressive capacity, can be read scientifically as an organ to be treated or symbolically as a part of the body capable of recording and expressing our psycho-emotional experience [21,22]. This is documented in "Item 27: I am embarrassed to speak because of the state of my mouth" and "Item 25: I am worried about my oral health" by PWS. In this context, attention to the role of emotions in oral life should involve both psychologists and dentists to maintain the psychosocial, physical and emotional well-being of PWS regarding oral health care.

More generally, emotional state is evidenced by PWS in the form of anxiety attacks (Item 1: I have anxiety attacks) and mood disorders (Item 12: I am lost in thought, replaying memories). Our results suggest that the pattern of stress experienced by PWS may be generated in part by poor oral health and that further research could contribute to psychosocial interventions to improve oral health (Item 37: I need help to manage my feelings). Oral health is severely impaired in these populations [4-7]. The SOHP scale will help to encourage caregivers to develop interpersonal skills (regular dental visits, brushing twice a day, reducing sugar intake ... ) to help restore oral health/global health.

The notion of pain and discomfort is a topic clearly expressed by PWS (Item 8: "My teeth hurt"; Item 16 "My mouth is sensitive to hot and cold") as in the general population. These data are interesting because it has long been thought that behavioural pain reactivity and self-reported pain responses are reduced in schizophrenia even though there is little or no physiological evidence to support pain insensitivity in PWS. The reduced sensitivity to pain in schizophrenia is thought to be related more to a different mode of pain expression than to actual endogenous analgesia [24]. To our knowledge, this is the first time that facial pain has been documented by an OHrQoL questionnaire (Item 10: "I have facial muscle pain"). This type of pain can be explained by the fact that these patients are exposed to a wide variety of drugs that may contribute to the increased occurrence of orofacial pain such as temporomandibular disorders [25]. 
In addition to pain, people with PWS also express their feelings about the oral cavity in detail (Item 17: "It hurts when I brush my teeth"). These complaints often take a back seat in PWS, in which stabilisation of symptoms remains the priority. Functional disorders (Item 22: "My mouth is dry or sticky"; Item 24: "I have difficulty chewing") highlight very specific disorders related to the use of anticholinergic drugs, which lead to a decrease in salivary secretion or even an alteration in salivary composition that is very disabling in daily life [26]. Saliva is a natural lubricant in the oral cavity and aids in the early stages of digestion. Surprisingly, among the discomforts felt, PWS express discomfort related to bleeding gums (Item 21: "My gums bleed"), which shows the attention that these people pay to their oral health and calls into question the idea that PWS are detached from somatic disorders [27].

The notion of self-image, the gaze of others, is an essential notion for PWS, as they suffer from stigmatisation and many prejudices [28-30]. It is interesting to note that PWS feel that "the gaze of others" clearly passes through the mouth with all the symbolism associated with it in relationships (Item 11: "My jaw and my teeth are not good"; Item14: "Because of the appearance of my mouth, I am afraid of the gaze of others"; Item 27: "The state of my mouth makes it difficult for me to smile"). PWS expressed the need for support in managing their oral health (Item 15: "I need care for my oral well-being (for my oral health)"; Item 41: "I need help to manage my health"). Mental illness greatly impacts daily life management, and seeking help is a first step on the road to the recovery of $\mathrm{oral} / \mathrm{mental} / \mathrm{global}$ health.

\section{Limitations}

This study has some limitations related to the participants' subjectivity towards oral disorders and their attention span and reasoning ability, given the stage of their mental illness. In addition, some patients were recruited during the COVID period, which exacerbated anxiety and depressive disorders and rendered dental practices difficult to access. It cannot be excluded that the responses to this questionnaire would have been different outside the pandemic. This suggests that follow-up studies with additional CFA should be conducted.

\section{Conclusions}

The SOHP was developed to assess the OHrQoL of PWS. The final version of the SOHP questionnaire consisted of 20 items and an internal structure composed of three dimensions: (1) emotions related to oral health, (2) pain and oral discomfort and (3) self-image, others' views and the need for care. We showed that the difficulty and discrimination indices of each of the 20 selected items are acceptable according to the Rasch model, as well as their inter-item and inter-score correlations $(\alpha=0.875)$. The psychometric study of the SOHP scale is still in progress to investigate reproducibility, sensitivity to change and external structure. The SOHP will allow for fine-tuned assessment of the oral health needs of PWS based on their perceptions rather than the point of view of caregivers.

Author Contributions: F.D. and N.R. contributed to the design of the work and the acquisition, analysis and interpretation of data. F.S.-P., I.R. and F.D. contributed to the design of the work; the acquisition, analysis and interpretation of data; and drafted the work or substantively revised it. G.A., A.D. and W.E.-H. contributed to the design of the work. F.S.-P. and I.R. contributed to the design of the work, interpretation of data and the creation of new software used in the work. A.D. and G.A. contributed to the design of the work and interpretation of data. All authors have read and agreed to the published version of the manuscript.

Funding: This research received no external funding.

Institutional Review Board Statement: The study was conducted according to the guidelines of the Declaration of Helsinki and approved by the Committee for the Protection of Persons of the Ile de France region (registration number: 2018-A02043-52) on 7 September 2018. 
Informed Consent Statement: Informed consent was obtained from each participant or their legal guardians for individuals under guardianship. In the latter case, the patient's legal guardian(s) signed the informed consent.

Data Availability Statement: The data that support the findings of this study are available from the corresponding author upon reasonable request.

Acknowledgments: We would like to thank all volunteers who participated in this study, as well the study staff, for their support.

Conflicts of Interest: The authors declare no conflict of interest.

\section{References}

1. Kurtz, M.M.; Wexler, B.E.; Fujimoto, M.; Shagan, D.S.; Seltzer, J.C. Symptoms versus neurocognition as predictors of change in life skills in schizophrenia after outpatient rehabilitation. Schizophr. Res. 2008, 102, 303-311. [CrossRef] [PubMed]

2. Gandré, C.; Coldefy, M. Disparities in the use of general somatic care among individuals treated for severe mental disorders and the general population in France. Int. J. Environ. Res. Public Health 2020, 17, 3367. [CrossRef] [PubMed]

3. Brämberg, E.B.; Torgerson, J.; Kjellström, A.N.; Welin, P.; Rusner, M. Access to primary and specialized somatic health care for persons with severe mental illness: A qualitative study of perceived barriers and facilitators in Swedish health care. BMC Fam. Pract. 2018, 19, 12. [CrossRef] [PubMed]

4. Gurbuz, O.; Alatas, G.; Kurt, E.; Issever, H.; Dogan, F. Oral health and treatment needs of institutionalized chronic psychiatric patients in Istanbul, Turkey. Community Dent. Health 2010, 27, 151-157.

5. Denis, F.; Milleret, G.; Wallenhorst, T.; Carpentier, M.; Rude, N.; Trojak, B. Oral health in schizophrenia patients: A French multi-center cross-sectional study. Presse Med. 2019, 48, e89-e99. [CrossRef]

6. Denis, F.; Goueslard, K.; Siu-Paredes, F.; Amador, G.; Rusch, E.; Bertaud, V.; Quantin, C. Oral health treatment habits of people with schizophrenia in France: A retrospective cohort study. PLoS ONE 2020, 15, e0229946. [CrossRef]

7. Kisely, S.; Baghaie, H.; Lalloo, R.; Siskind, D.; Johnson, N. A systematic review and meta-analysis of the association between poor oral health and severe mental illness. Psychosom. Med. 2015, 77, 83-92. [CrossRef]

8. Tiihonen, J.; Lönnqvist, J.; Wahlbeck, K.; Klaukka, T.; Niskanen, L.; Tanskanen, A.; Haukka, J. 11-year follow-up of mortality in patients with schizophrenia: A population-based cohort study (FIN11 study). Lancet 2009, 374, 620-627. [CrossRef]

9. Denis, F.; Hamad, M.; Trojak, B.; Tubert-Jeannin, S.; Rat, C.; Pelletier, J.-F.; Rude, N. Psychometric characteristics of the “General Oral Health Assessment Index (GOHAI) » in a French representative sample of patients with schizophrenia. BMC Oral Health 2017, 17, 75. [CrossRef]

10. Frederic, D.; Corinne, R.; Matthieu, R.; Francesca, S.P.; Stephanie, T.J.; Nathalie, R. The schizophrenia oral health profile: Development and feasibility. Transl. Neurosci. 2018, 9, 123-131. [CrossRef]

11. Bland, J.M.; Altman, D.G. Cronbach's alpha. BMJ 1997, 314, 572. [CrossRef] [PubMed]

12. Hwang, I.H. The usability of item-total correlation as the index of item discrimination. Korean J. Med. Educ. 2000, 12, 45-51. [CrossRef]

13. Bond, T.G.; Fox, C.M. Applying the Rasch Model: Fundamental measurement in the human sciences. J. Educ. Meas. 2003, 40, 185-187. [CrossRef]

14. Pett, M.; Lackey, N.R.; Sullivan, J.J. Making Sense of Factor Analysis; SAGE Publications Inc.: Thousand Oaks, CA, USA, 2003.

15. Yong, A.G.; Pearce, S. A beginner's guide to factor analysis: Focusing on exploratory factor analysis. Tutor. Quant. Methods Psychol. 2013, 9, 79-94. [CrossRef]

16. Tavakol, M.; Dennick, R. Psychometric evaluation of a knowledge based examination using Rasch analysis: An illustrative guide: AMEE Guide No. 72. Med. Teach. 2012, 35, e838-e848. [CrossRef] [PubMed]

17. Yang-Wallentin, F.; Jöreskog, K.G.; Luo, H. Confirmatory factor analysis of ordinal variables with misspecified models. Struct. Equ. Model. A Multidiscip. J. 2010, 17, 392-423. [CrossRef]

18. Oral Health Surveys: Basic Methods, 5th ed.; WHO: Geneva, Switzerland, 2013.

19. Oral Hygiene Index Greene and Vermilion. 1960. Available online: http:/ / www.mah.se (accessed on 20 July 2021).

20. Settineri, S.; Mallamace, D.; Muscatello, M.R.A.; Zoccali, R.; Mento, C. Dental anxiety, psychiatry and dental treatment: How are they linked? Open J. Psychiatry 2013, 3, 168-172. [CrossRef]

21. Settineri, S.; Rizzo, A.; Ottanà, A.; Liotta, M.; Mento, C. Dental aesthetics perception and eating behavior in adolescence. IJAMH 2015, 27, 311-317. [CrossRef]

22. Settineri, S.; Rizzo, A.; Liotta, M.; Mento, C. Clinical psychology of oral health: The link between teeth and emotions. SAGE Open 2017, 7. [CrossRef]

23. Polmann, H.; Réus, J.C.; Massignan, C.; Serra-Negra, J.M.; Dick, B.D.; Flores-Mir, C.; Lavigne, G.J.; Canto, G.D.L. Association between sleep bruxism and stress symptoms in adults: A systematic review and meta-analysis. J. Oral Rehabil. 2020, 48, 621-631. [CrossRef]

24. Bonnot, O.; Anderson, G.; Cohen, D.; Willer, J.C.; Tordjman, S. Are patients with schizophrenia insensitive to pain? A reconsideration of the question. Clin. J. Pain 2009, 25, 244-252. [CrossRef] [PubMed] 
25. de Araújo, A.N.; do Nascimento, M.A.; de Sena, E.P.; Baptista, A.F. Temporomandibular disorders in patients with schizophrenia using antipsychotic agents: A discussion paper. Drug Healthc. Patient Saf. 2014, 6, 21-27. [PubMed]

26. Chapuis, J.; Siu-Paredes, F.; Pavageau, C.; Amador, G.; Rude, N.; Denis, F. The impact of anticholinergic drugs in oral health related quality of life for persons with schizophrenia: A pilot study. Transl. Neurosci. 2020, 11, 10-16. [CrossRef] [PubMed]

27. Oud, M.J.T.; Jong, B.M.-D. Somatic diseases in patients with schizophrenia in general practice: Their prevalence and health care. BMC Fam. Pract. 2009, 10, 32. [CrossRef]

28. Kim, J.-H.; Shin, Y.-J.; Joo, Y.-H. Self-perceived cognitive deficits and their relationship with internalized stigma and quality of life in patients with schizophrenia. Neuropsychiatr. Dis. Treat. 2016, 12, 1411-1417. [CrossRef] [PubMed]

29. Barlati, S.; Morena, D.; Nibbio, G.; Cacciani, P.; Corsini, P.; Mosca, A.; Deste, G.; Accardo, V.; Turrina, C.; Valsecchi, P.; et al. Internalized stigma among people with schizophrenia: Relationship with socio-demographic, clinical and medication-related features. Schizophr. Res. 2021. [CrossRef] [PubMed]

30. Guan, Z.; Huang, C.; James, A.; Wiley, J.A.; Sun, M.; Bai, X.; Tang, S. Internalized stigma and its correlates among family caregivers of patients diagnosed with schizophrenia in Changsha, Hunan, China. J. Psychiatr. Ment. Health Nurs. 2020, 27, 224-236. [CrossRef] [PubMed] 